\title{
Possession of Flagellar Hooks by Some Non-flagellate Mutants of Salmonella abortusequi
}

\author{
By S. YAMAGUCHI* AND T. IINO \\ National Institute of Genetics, I, I I Y Yata, Misima, Sizuoka-ken, Japan \\ AND T. KUROIWA \\ Tokyo Metropolitan Isotope Research Centre, 2-I I-I Fukazawa, \\ Setagaya-ku, Tokyo, Japan
}

(Accepted for publication 10 November I97I)

SUMMARY

The possession of flagellar hooks by non-flagellate mutants derived from phase I stable strains of Salmonella abortusequi was determined by electron microscopic examination of material detached from these bacteria by mechanical means. Hooks were found in all the preparations from $H I$ mutants but none in those from $\mathrm{fla}$ mutants representative of fourteen different complementation groups. The hooks from $H I$ mutants were morphologically indistinguishable from those of wild-type. These results show that all the $f l a$ genes are involved in hook formation and that the flagellin structural gene $H I$ is not.

\section{INTRODUCTION}

A bacterial flagellum is composed of a filament, hook, and basal body (Abram, Vatter \& Koffler, 1965, I966; Cohen-Bazire \& London, 1967). The filament is the distal helical part of the flagellum, and is a polymer of flagellin. The basal body is the proximal structure, bound to the cell wall and membrane (DePamphilis \& Adler, 197I). The hook connects the filament to the basal body. Both filaments and hooks can be detached from flagellated cells by mechanical shaking (Abram, Mitchen, Koffler \& Vatter, 1970).

In Salmonella, the non-flagellate phenotype results from mutation in either the $H$ or $f l a$ genes (Iino, 1969a). The $H$ genes, $H I$ and $H_{2}$, are the structural genes for the phase I and the phase 2 flagellins, respectively. The precise functions of $f a$ genes are not known. Fourteen $f l a$ complementation groups have been recognized (Joys \& Stocker, 1965; Iino \& Enomoto, I966; Yamaguchi \& Iino, I969; Yamaguchi, Iino, Horiguchi \& Ohta, I972). Socalled non-flagellate mutants lack the filament, but it is not known if they possess other parts of the flagellum. In this study the possession of hooks by non-flagellate mutants, including both those representative of almost all fla complementation groups and $H I$ mutants derived from phase I of stable strains Salmonella abortusequi SL23, was determined by electron microscope observation of material mechanically detached from bacteria.

\section{METHODS}

Bacteria. SJ24I $(H I-a)$ is a phase I stable derivative of Salmonella abortusequi SL23. Non-flagellate strains, SJW4I2, SJW4I4 and SJW4I7, are $H I$ mutants of SJ24I. The $f a$ strains

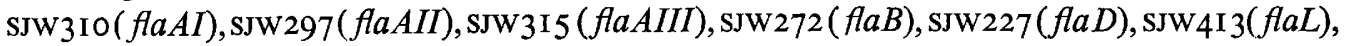

* Present address: Department of Biology, School of Education, Waseda University, Totsuka-machi, Shinjuku-ku, Tokyo, Japan 
SJW29I ( flaN), SJW337 ( $f l a P$ ) and SJW246 ( $f l a Q$ ) are mutants of SJ24I. Other fla strains, SJWI4I

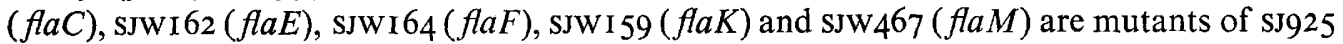
( $H I-g t)$, a derivative of SJ24I, in which $H_{I-a}$ of SJ24I was replaced by HI-gt of Salmonella budapest strain su6 by transduction.

Media. Nutrient broth was $\mathrm{I} \%(\mathrm{w} / \mathrm{v})$ peptone and $\mathrm{I} \%(\mathrm{w} / \mathrm{v})$ meat extract in $0.05 \mathrm{M}-$ phosphate buffer $\left(\mathrm{pH}_{7} \cdot 2\right)$, to which $\mathrm{I} \cdot 5 \%(\mathrm{w} / \mathrm{v})$ agar was added to give nutrient agar.

Isolation of hooks from non-flagellate mutants. Ten $\mathrm{ml}$ quantities of overnight broth cultures of non-flagellate strains were spread on to nutrient agar in trays $(20 \times 30 \times \mathrm{I} \cdot 8 \mathrm{~cm})$. After incubation for $24 \mathrm{~h}$ at $37^{\circ}$, bacteria were harvested in $0.85 \%$ saline, and centrifuged at I0,000 $\mathrm{g}$. Approximately Io g bacteria (wet weight) were suspended in $100 \mathrm{ml}$ saline, and $\mathrm{Io} \mathrm{g}$ fine glass beads added. This suspension was shaken at 750 strokes $/ \mathrm{min}$ ( $25 \mathrm{~mm}$ amplitude) for $30 \mathrm{~min}$ and centrifuged at $10,000 \mathrm{~g}$ to remove bacteria. The supernatant was centrifuged

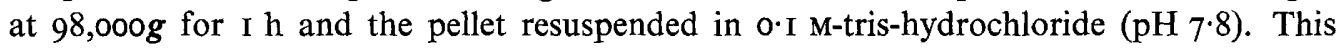
suspension was then given two cycles of differential centrifugation first at $10,000 \mathrm{~g}$ for $10 \mathrm{~min}$ to sediment bacterial debris and then at $98,000 \mathrm{~g}$ for $\mathrm{I} \mathrm{h}$ to sediment hooks. A small portion of this pellet was resuspended in distilled water and observed with the electron microscope. If hooks were seen the remainder of the pellet was resuspended in I $\mathrm{ml} 0.1 \mathrm{M}$-tris-hydrochloride ( $\mathrm{pH} 7.8$ ), to which $0 . \mathrm{I} \mathrm{ml} 0.2 \%$ lysozyme in 0.1 M-tris-hydrochloride $(\mathrm{pH} 7.8)$ and I $\mathrm{ml} 2 \%$ Brij-58 in the same buffer were added to lyse remaining cell debris. After incubation at $30^{\circ}$ for $30 \mathrm{~min}$, dilution to $30 \mathrm{ml}$ with distilled water and centrifugation at $98,000 \mathrm{~g}$ for $\mathrm{I} h$, the final pellet was resuspended in $0.5 \mathrm{ml}$ distilled water and observed with the electron microscope.

Isolation of hooks from flagellate bacteria. Flagella were isolated and partially purified as described by Yamaguchi \& Iino (1969), and crude preparations of hooks obtained from them as follows. Flagella were suspended in distilled water to a final concentration of $10 \mathrm{mg}$ flagella $/ \mathrm{ml}$. One $\mathrm{ml}$ of the suspension was heated at $60^{\circ}$ for $10 \mathrm{~min}$, cooled to $20^{\circ}$, and centrifuged at $98,000 \mathrm{~g}$ for $\mathrm{I} \mathrm{h}$, and the pellet resuspended in $0.5 \mathrm{ml}$ distilled water and observed with the electron microscope. Such preparations contained many isolated hooks and a few filaments, most of which had a hook at one end.

Electron microscopy. Samples were negatively stained with I\% uranyl acetate ( $\mathrm{pH} 4 \cdot 0)$ and then examined with a JEM 7 A electron microscope.

Chemical. Egg white lysozyme (three times crystallized) was obtained from Seikagaku Kogyo Co., Tokyo, Japan. Brij-58 was obtained from Wako Pure Chemical Industries Co., Osaka, Japan.

\section{RESULTS}

Hooks were isolated from all the $H I$ mutants, but not from any of the fla mutants examined.

After the two cycles of differential centrifugation, the preparations from $\mathrm{HI}$ mutants contained both hooks and many membraneous particles; the majority of the latter were removed by treatment with lysozyme and Brij-58. In the preparation from SJW337 ( flaP) a few flagella were observed and as this strain is known to be leaky, the flagella observed were likely to have been those detached from the few flagellate bacteria in the culture.

Hooks obtained from $H I$ mutants were of almost uniform length $(72 \pm 8 \mathrm{~nm})$ and diameter ( $18 \mathrm{~nm}$ ) (Fig. I). Their size and shape were indistinguishable from those of the parent strain SJ24I (Fig. 2). One end of these hooks appeared to be frayed or split and the other end blunt (Fig. I, 2 and 3).

From the observation that Escherichia coli hooks showed either a cross-hatched surface pattern or one consisting of parallel lines oblique to the axis of the hook, DePamphilis \& 

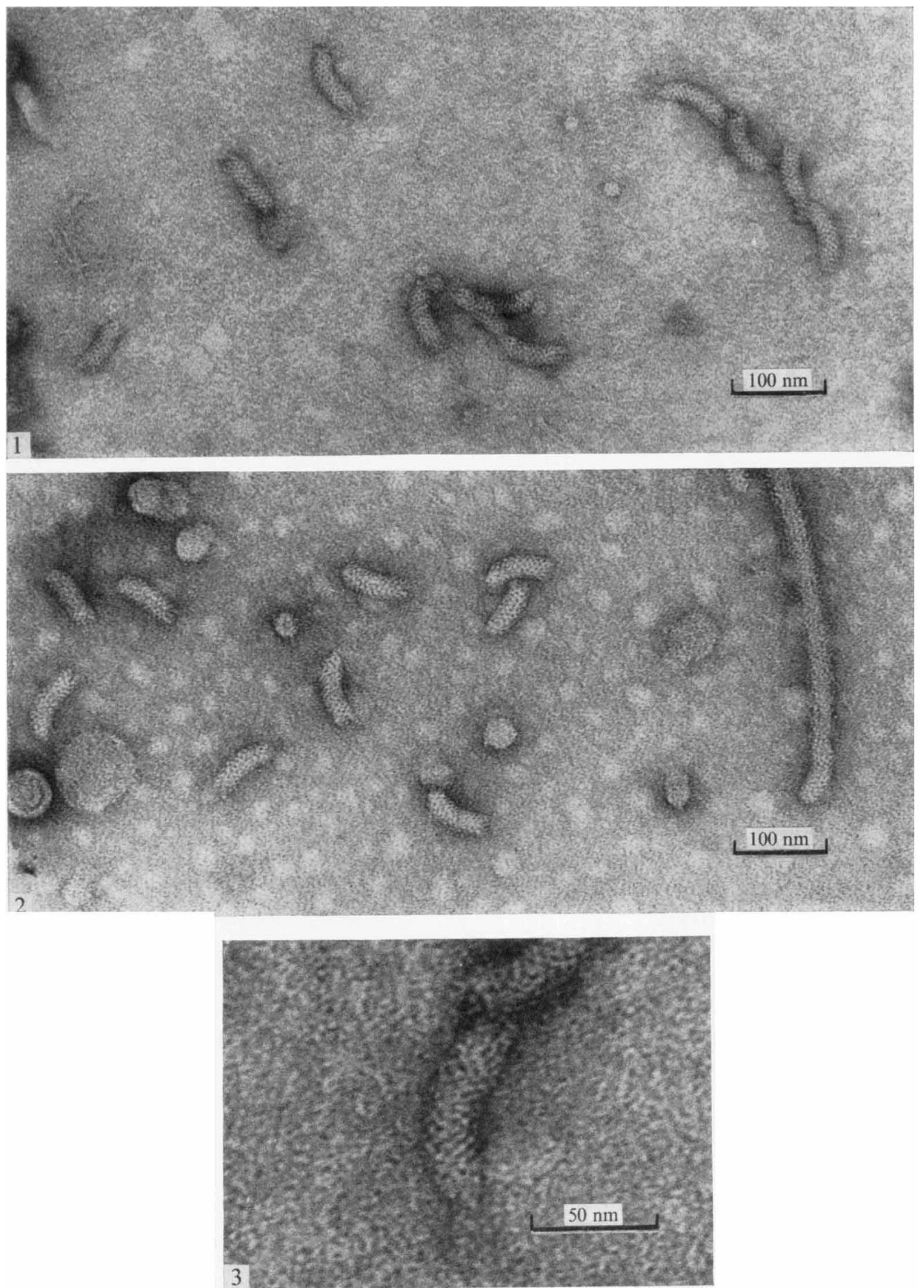

Fig. I. Hooks isolated from sJw4I7, an $H_{\mathrm{I}}$ mutant of phase I stable Salmonella abortusequi strain SJ24I.

Fig. 2. Hooks and a flagellum isolated from Salmonella abortusequi strain sJ24I. Round bodies are vesicular fragments of the cell envelope.

Fig. 3. A hook isolated from ssw4I7.

All the samples were stained with I \% uranyl acetate. 
Adler (I97I) proposed a structure comprising several helical coils. They suggested that the first pattern would be the superimposed images of the top and bottom surfaces of the hook and the second a view of one side. Many of the hooks we observed seemed to be more complex; each consisting of a part with a cross-hatched pattern, another showing parallel oblique lines and another appearing hazy (Fig. 3). Such patterns suggest a structure composed of several fine coils and twisted to form a short helix of relatively small pitch.

\section{DISCUSSION}

Hook and filament are not only distinguishable morphologically, they also differ in serological specificity (Lawn, 1967) and solubility in acid and/or alcohol (Abram et al. 1970). However, it is still possible that they are both composed of flagellin molecules in different conformational states. The presence of hooks in $H I$ mutants showed that hook formation is not under the control of the flagellin structural gene. A similar result was also obtained with Salmonella typhimurium (R. J. Martinez, personal communication).

It has been proposed that $f l a$ either produces an internal inducer for flagellin synthesis, or controls the production of a component of the whole flagellum-forming apparatus (Iino, r $969 a$ ). The absence of hooks as well as filaments from the $f a$ mutants favours the second hypothesis. In Escherichia coli eight different structures have been distinguished in the hookbasal body complex (DePamphilis \& Adler, I97I), and this could imply the involvement of as many as eight different fla genes. If this is so, how does the fla region control the formation of the hook and/or the filament besides being involved in the formation of some specific structure? An examination of $f a$ mutants for basal body defects could aid understanding of the function of $f l a$ genes.

It has been shown that flagellar filaments have a structural polarity, i.e. only the distal ends of the fragments of the filaments appear to be frayed, and that they are formed by a sequential polymerization of flagellin molecules at the distal end of each filament (Asakura, Eguchi \& Iino, 1968; Iino, 1969 b). The structural similarity of the distal frayed end of the hook (Fig. 3) to that of the filament may also indicate formation of the hook by sequential polymerization of subunit molecules. As hooks are about the same length irrespective of the presence or absence of the filaments it is suggested that their maximum length is limited by some factor, and that the possibility of the addition of flagellin to these distal ends being the limiting factor is excluded. It is also difficult to visualize the existence of a core determining the length of the hook, if the observed cross-hatched pattern of the hook (Fig. 3) really represents the superimposed image of the upper and lower surfaces of the hook.

Hooks are supposed to serve as the initiation points for polymerization of flagellin into the filaments. We have obtained provisional evidence that the hooks of $H_{I}$ mutants are involved in the initiation of polymerization of external flagellin into filaments.

This paper is Contribution no. 866 from the National Institute of Genetics.

\section{REFERENCES}

Abram, D., Mitchen, J. R., Koffler, H. \& Vatter, A. E. (I970). Differentiation within the bacterial flagellum and isolation of the proximal hook. Journal of Bacteriology ror, 250-26r.

Abram, D., Vatter, A. E. \& Koffler, H. (1965). Basal structure and attachment of flagella in cells of Proteus vulgaris. Journal of Bacteriology 90, $1337-1354$.

Abram, D., Vatter, A. E. \& Koffler, H. (1966). Attachment and structural features of flagella of certain bacilli. Journal of Bacteriology 95, 2045-2068. 
AsAKURA, S., EGUCHI, G. \& IINO, T. (1968). Unidirectional growth of Salmonella flagella in vitro. Journal of Molecular Biology 35, 227-236.

CoHEN-BAZIRE, G. \& London, J. (1967). Basal organelles of bacterial flagella. Journal of Bacteriology 94, $458-465$.

DePamphilis, M. L. \& AdLer, J. (197I). Fine structure and isolation of the hook-basal body complex of flagella from Escherichia coli and Bacillus subtilis. Journal of Bacteriology 105, 384-395.

IINo, T. (1969a). Genetics and chemistry of bacterial flagella. Bacteriological Reviews 33, 454-475.

IINo, T. (1969 b). Polarity of flagellar growth in Salmonella. Journal of General Microbiology 56, 227-239.

InNo, T. \& ENOMOTo, M. (1966). Genetical studies of non-flagellate mutants of Salmonella. Journal of General Microbiology 43, 315-327.

JOYs, T. M. \& STOCKER, B. A. D. (1965). Complementation of nonflagellate Salmonella mutants. Journal of General Microbiology 4I, 47-55.

LAWN, A. M. (1967). Simple immunologicallabelling method for electron microscopy and its application to the study of filamentous appendages of bacteria. Nature, London 2I4, I I 5 I-I I 52.

YAMAGUCHI, S. \& IINo, T. (1969). Genetic determination of the antigenic specificity of flagellar protein in Salmonella. Journal of General Microbiology 55, 59-74.

Yamaguchi, S., Iino, T., Horiguchi, T. \& OHTA, K. (I972). Genetic analysis of $f a$ and mot cistrons closely linked to HI in Salmonella abortusequi and its derivatives. Journal of General Microbiology, 7o, 59-76. 